\title{
Sejarah Hutan Mangrove Tongke-Tongke di Kabupaten Sinjai
}

Reskiayu Lestari, Amirullah, Ahmadin.

Prodi Pendidikan Sejarah Fakultas Ilmu Sosial Universitas Negeri Makassar, Indonesia reskiayuakib@gmail.com, amirullah8505@unm.ac.id,ahmadin@unm.ac.id

\begin{abstract}
Abstrak
Penelitian dan penulisan ini bertujuan untuk mendeskripsikan latar belakang keberadaan hutan mangrove, perkembangan hutan mangrove, menguraikan dampak keberadaan hutan mangrove terhadap kehidupan sosial, ekonomi, dan pariwisata di Desa Tongke - Tongke Kecamatan Sinjai Timur Kabupaten Sinjai. Penelitian ini menggunakan metode penelitian sejarah yang terdiri dari 4 tahap, yakni: heuristik, kritik sumber, interpretasi, dan historiografi. Metode pengumpulan data dilakukan dengan cara penelitian lapangan terdiri dari wawancara dan studi pustaka. Penulisan skripsi ini digolongkan sebagai sejarah ekowisata. Hasil penelitian menunjukkan bahwa latar belakang keberadaan hutan mangrove di Desa Tongke - Tongke karena terjadinya abrasi yang melanda wilayah pesisir Tongke - Tongke. Pada tahun 1985 masyarakat mulai menanam mangrove untuk mencegah terjadinya abrasi. Hutan mangrove ini merupakan hasil rehabilitasi masyarakat secara swadaya. Perkembangan hutan mangrove Tongke - Tongke terjadi tahun 1995 setelah mendapat piagam penghargaan Kalpataru sebagai penyelamat lingkungan hingga menjadi sebuah obyek wisata. Obyek wisata hutan mangrove Tongke - Tongke ramai dikunjungi oleh wisatawan serta menjadi laboratorium pengembangan mangrove di Sulawesi Selatan. Keberadaan hutan mangrove ini memberi dampak sosial, ekonomi dan pariwisata bagi masyarakat. Berdasarkan hasil penelitian, maka dapat disimpulkan bahwa keberadaan hutan mangrove hingga mengalami perkembangan pesat terutama setelah menjadi obyek wisata alam yang menyebabkan banyak wisatawan yang datang berkunjung ataupun melakukan penelitian dan ini berdampak pada pelaku ekonomi yang turut berpartisipasi serta memanfaatkan peluang untuk meningkatkan kehidupan ekonomi yang lebih baik.
\end{abstract}

Kata kunci: Mangrove, Wisata, Tongke-tongke

\section{Abstract}

This research and writing aims to describe the background of the existence of mangrove forests, the development of mangrove forests, outlining the impact of the existence of mangrove forests on social life, economy, and tourism in the Village of Tongke - Tongke, Sinjai Timur District, Sinjai District. this thesis is classified as the history of ecotourism. . This study uses a historical research method consisting of 4 stages, namely: heuristic, source criticism, interpretation, and historiography. Data collection methods are done by how a field research is made up of interviews and literature study. The results showed that the background of the existence of mangrove forests in the village of Tongke - Tongke due to abrasion that struck the coastal areas of Tongke - Tongke. In 1985 the community began planting mangroves to prevent abrasion. This mangrove forest is the result of community self-help rehabilitation. The development of the Tongke - Tongke mangrove forest took place in 1995 after receiving a Kalpataru award as a savior of the environment to become a tourist attraction. Tourism object of Tongke - Tongke mangrove forest is visited by tourists and becomes a laboratory for mangrove development in South Sulawesi. The existence of this mangrove forest has a social, economic and tourism impact on the community. Based on the results of the study, it can be concluded that the existence of mangrove forests has experienced rapid development especially after becoming a natural tourist attraction which has caused many tourists to visit or conduct research and this has an impact on economic actors who participate and take advantage of opportunities to improve economic life

Keywords: Mangrove, Tourism, Tongke-tongke 


\section{A. Pendahuluan}

Secara ekologis hutan mangrove berperan sebagai pelindung pantai dari bahaya tsunami, penahan erosi dan perangkap sedimen, pendaur hara, menjaga produktivitas perikanan, peredam laju intrusi air laut, penyangga kesehatan, menjaga keanekaragaman hayati, dan menopang ekosistem pesisir lainnya. (Tuwo, 2011).

Banyak diantara warga masyarakat yang pada akhirnya sadar dan mau untuk menanam mangrove, terutama jika mereka merasakan ada kaitannya dengan hasil ikan yang mereka dapatkan atau manfaat lainnya. (Karminarsih, 2007)

Wilayah pesisir pantai yang ditumbuhi mangrove salah satunya terdapat di Desa Tongke - Tongke. Hutan mangrove yang ada di Tongke - Tongke merupakan hutan buatan yang dibangun oleh masyarakat setempat. Masyarakat Desa Tongke Tongke telah berhasil membangun sebuah kawasan hutan mangrove yang lebat secara swadaya dengan tujuan awal sebagai perlindungan dari abrasi. Karena letaknya berada dipesisir sehingga jika air pasang maka air laut masuk ke pemukiman penduduk.

Mangrove sangat berpotensi di gunakan sebagai ekowisata. Hal ini dikarenakan kondisi mangrove yang sangat unik dan model wilayah yang dikembangkan sebagai sarana wisata tetap memerhatikan keaslian hutan dan organisme yang hidup didalamnya. (Rangkuti, 2017). Kawasan hutan mangrove yang ada di Desa Tongke - Tongke memiliki keunikan karena potensi hutan mangrove yang dibangun dari swadaya masyarakat telah menjadi hutan lindung dan kini telah dijadikan tempat wisata oleh pemerintah setempat dan menjadi tempat laboratorium pengembangan mangrove.

Kajian relevan dalam suatu karya ilmiah perlu untuk di telusuri guna mencari tahu apakah ide pokok suatu kajian sudah di angkat oleh penulis lain atau belum. Penelitian ini berusaha untuk mengkaji mengenai Hutan Mangrove di Desa Tongke - Tongke Kabupaten Sinjai.

Adapun sumber dan referensi yang ditemukan terkait tentang Hutan Mangrove yaitu buku : "Pengelolaan Ekowisata Pesisir dan Laut" yang ditulis oleh Ambo Tuwo, DEA tahun 2011 merupakan sumber untuk memahami produktivitas pengembangan hutan mangrove sebagai ekowisata. Buku dengan judul Pengelolaan Perikanan Indonesia yang ditulis oleh M.Ghufran H. Kordi K tahun 2015 merupakan sumber untuk memahami potensi hutan mangrove. . (M.Ghufran H, 2015)

Skripsi yang ditulis oleh Asfar Rusydi tahun 2017 dengan judul "Masyarakat Desa Tongke - Tongke Dalam Pelestarian Lingkungan Hutan Mangrove di Kabupaten Sinjai". Dalam pembahasan skripsi ini difokuskan pada peran masyarakat dalam melestarikan hutan mangrove di Desa Tongke -Tongke, pandangan masyarakat Tongke-Tongke tentang manfaat yang diperoleh dari pengembangan pelestarian lingkungan hutan mangrove, dan bagaimana pengetahuan lokal masyarakat Tongke - Tongke dalam melestarikan hutan mangrove. Sedangkan dalam penelitian ini mengkaji tentang latar belakang keberadaan hutan mangrove di Desa Tongke-Tongke hingga menjadi kawasan wisata hutan mangrove.

Jurnal Emi Karminarsih fakultas Kehutanan IPB ,Vol XIII 2007 dengan judul Pemanfaatan Ekosistem Mangrove Bagi Minimasi Dampak Bencana Diwilayah Pesisir.

\section{B. Metode Penelitian}

Metode penelitian yang digunakan ialah kualitatif. Metode ini sering digunakan dalam ilmu sejarah dan ilmu sosial lainnya dengan tujuan untuk menemukan suatu hal yang unik dan mampu mengungkapkan peristiwa yang telah terjadi di masa lampau. (Priyadi, 2012)

Penelitian ini diarahkan untuk meneliti, mengungkapkan serta 
menjelaskan latar belakang serta perkembangan hutan mangrove di Desa Tongke - Tongke, sehingga jelas diarahkan kepada metode penelitian sejarah yang bersifat kualitatif.

Metode berbeda dengan metodologi. Menurut Kenneth D. Bailey, metode adalah teknik penelitian atau alat yang dipergunakan untuk mengumpulkan data. (Madjid, 2008)

Berdasarkan uraian tersebut di atas dapat disimpulkan bahwa metode sejarah merupakan cara atau tehnik dalam merekontruksi peristiwa masa lampau, melalui empat tahapan kerja yaitu heuristic (pengumpulan sumber), kritik sumber (eksternal bahan dan internal isi), interpretasi (penafsiran), dan historigrafi (penulisan Sejarah).

\section{Heuristik}

Heuristik merupakan langkah awal dari metode penelitian sejarah, dimana pada tahap ini seorang peneliti mencari dan mengupayakan penemuan atas sumber sejarah yang memilki keterkaitan dengan objek penelitian.

Dalam melakukan pengumpulan sumber, peneliti menempuh dua cara:

\section{a. Penelitian Pustaka}

Studi pustaka merupakan salah satu langkah penting dalam penelitian sejarah. Dalam studi pustaka ini akan dilakukan studi terhadap sejumlah bahan pustaka, baik yang berupa arsip, buku, dan hasil penelitian lainnya yang memiliki kaitan dengan topik penelitian ini. Bahan-bahan pustaka tersebut akan penulis peroleh dari Perpustakaan Sejarah FIS-UNM, Perpustakaan UNHAS, dan Kantor Desa Tongke - Tongke.

\section{b. Penelitian Lapangan}

Kegiatan yang akan dilakukan dalam penelitian lapangan adalah mengadakan pegumpulan data secara langsung terhadap obyek yang menjadi sasaran penelitian. Dalam hal ini peneliti menggunakan kegiatan observasi dan pedoman wawancara. Kegiatan tersebut di jelaskan sebagai berikut :

1) Observasi
Observasi adalah pengamatan secara langsung terhadap objek yang akan diteliti atau terhadap lokasi penelitian. Metode observasi yang peneliti maksud adalah mengadakan pengamatan dan penginderaan langsung terhadap masyarakat atau objek penelitian. Dalam hal ini peneliti akan melakukan observasi pada tempat peneliti melakukan penelitian yaitu di Desa Tongke - Tongke yang terkait dengan Hutan Mangrove.

\section{2) Wawancara}

Peneliti melakukan wawancara terhadap orang yang dianggap berkompeten dalam objek yang diteliti. Wawancara dilakukan dengan $\mathrm{H}$. Taiyeb pelopor hutan mangrove di Desa Tongke - Tongke, Sainuddin ketua kelompok ACI, dan masyarakat disekitar kawasan hutan mangrove. Hasil wawancara kemudian dapat direkam dan tau dicatat untuk selanjutnya diperbaiki pada saat penyusunan laporan penelitian. Selain itu, peneliti juga menggunakan dokumentasi penelitian. Hal tersebut dilakukan agar data yang diperoleh peneliti sifatnya obyektif dan dapat dipertanggung jawabkan.

\section{Kritik}

Jika sumber-sumber yang digunakan sudah dianggap cukup, langkah selanjutnya adalah menilai sumber tersebut untuk menyeleksi dan menguji kebenaran dan keabsahan suatu sumber, guna mendapatkan data yang otentik. Dalam kritik sumber, terdapat penekanan tertentu yang bertujuan untuk memberikan definisi kritik sumber itu sendiri. Tujuan dari kegiatan-kegiatan ini adalah bahwa setelah sejarawan berhasil mengumpulkan sumbersumber dalam penelitiannya, ia tidak akan menerima begitu saja apa yang tercantum dan tertulis pada sumber-sumber itu. (Helius, 2012)

\section{Interpretasi}

Pada tahap ini sumber atau data sejarah yang telah diseleksi dapat digunakan sebagai sumber atau bahan penulisan sejarah, namun sumber tersebut masih 
harus dilakukan penelitian lebih lanjut yang dikenal dengan interpretasi (penafsiran). Dalam tahap ini penulis dituntut untuk bisa menghasilkan interpretasi yang tidak memihak dan sesuai dengan kebenaran fakta yang ada karena unsur subjektivitas terkadang dapat mempengaruhi isi penulisan..

\section{Historiografi}

Pada tahap terakhir ini, data-data yang telah diseleksi oleh peneliti melalui tiga tahapan sebelumnya kemudian dituliskan dalam bentuk kisah sejarah. Historiografi merupakan puncak dari segala-galanya dalam metode penelitian sejarah. Sejarawan pada fase ini mencoba menangkap dan memahami histoire realite atau sejarah sebagaimana terjadinya.

\section{Hasil dan Pembahasan}

\section{Latar Belakang Keberadaan Hutan Mangrove}

Hutan mangrove adalah hutan pantai yang selalu atau secara teratur tergenang air laut dan dipengaruhi oleh pasang surut air laut. Mangrove adalah sebutan umum yang di gunakan untuk menggambarkan varietas komunitas pantai tropik yang didominasi oleh beberapa jenis pohon dan semak yang khas yang mempunyai kemampuan untuk tumbuh dalam perairan asin (Tuwo, 2011)

Ekosistem mangrove di Desa Tongke Tongke merupakan hasil rehabilitasi pantai yang pada awalnya dilakukan masyarakat secara swadaya untuk menyelamatkan lingkungan dari abrasi pantai. (H.Taiyeb, 2019)

Penanaman hutan mangrove di Tongke - Tongke dilatarbelakangi oleh terjadinya abrasi yang terus terjadi di Tongke Tongke sejak tahun 1984 khususnya di dusun Cempae dan Babana. Karena letaknya berada di wilayah pesisir sehingga ketika gelombang pasang maka pemukiman tergenang air dan ombak yang tinggi menghantam perahu dan tambak masyarakat.

Masyarakat berupaya mengatasi kondisi alam dengan membangun tanggul penahan ombak yang di buat dari batu karang sepanjang 30 meter yang di dapatkan dari pulau. Batu karang di ambil selepas shalat jumat dan berlangsung selama satu tahun, namun ternyata tanggul batu tersebut tidak bertahan lama, hanya dalam waktu beberapa bulan tanggul sudah hancur di hempas ombak sehingga usaha masyarakat sia - sia.

Kegagalan pembuatan tanggul pada tahun 1984 merupakan titik balik kesadaran masyarakat bahwa tanggul batu tidak dapat melindungi wilayah pesisir dari abrasi saat gelombang pasang bahkan untuk melingdungi dan mengamankan daerah tambat perahu nelayan yang bermukim disitu seperti nelayan tradisional panaikang (Haerianty Rezki Sani, Amirullah, 2018). Kesadaran tersebut kemudian mendorong beberapa tokoh masyarakat untuk bermusyawarah dan bersepakat melakukan penyelamatan lingkungan melalui penanaman mangrove.

Kegiatan penanaman mangrove yang dilakukan masyarakat karena kemauan sendiri dan kesadaran melihat pantai yang semakin terkikis akibat abrasi dan berdampak langsung bagi masyarakat.Masyarakat Tongke - Tongke melakukan penanaman mangrove karena melihat desa tetangga yaitu Desa Pangasa yang menanam mangrove untuk melindungi tambak mereka dari arus gelombang. Masyarakat berfikir jika hal ini juga dilakukan di Desa Tongke - Tongke maka kemungkinan abrasi pantai dapat dihalau dengan keberadaan mangrove.

Penanaman mangrove ini dipelopori oleh salah satu tokoh masyarakat yaitu $\mathrm{H}$. Taiyeb. Penanaman pertama dilakukan oleh 10 orang tokoh masyarakat. Penanaman ini dimotori oleh $\mathrm{H}$. Badaruddin sebagai kepala lingkungan dan 9 tokoh masyarakat diantaranya H. Taiyeb, Sainuddin, Sirajuddin, H. Abdul Kadir, H.Usman, Amiruddin, Pettafala, Gopa, dan Asri. (Sainuddin, 2019)

\section{a. Penanaman Hutan Mangrove}

Sebelum melakukan penanaman mangrove pada tahun 1985 masyarakat melakukan pertemuan untuk 
bermusyawarah yang bertempat di rumah H. Abdul Kadir dan membagi lahan yang ingin ditanami ke tiap - tiap keluarga agar kedepannya tidak muncul masalah mengenai kepemilikan mangrove. Pertemuan ini terkait dengan formasi penanaman mangrove yang bertujuan agar menghindari dampak sosial terhadap masyarakat nelayan dan petani mangrove sehingga disepakati ada jalur pendaratan perahu nelayan dan ada tempat penanaman mangrove sendiri sehingga tercipta kebersamaan dalam penanaman mangrove.

Vegetasi mangrove dapat hidup dan tumbuh optimal apabila berada di wilayah pesisir yang terdapat muara sungai cukup besar dan daerah delta dimana aliran airnya terdapat banyak kandungan lumpur. (Nuddin, 2016)

Sebelum melakukan penanaman terlebih dahulu di lakukan peninjauan lokasi. Lokasi yang di pilih untuk menanam bakau adalah berlumpur dan berpasir agar mangrove dapat tumbuh dengan baik.

Pada tahun 1985 penanaman mulai di lakukan secara swadaya oleh masyarakat di dusun Cempae. Adapun waktu tertentu untuk menanam bakau adalah bulan September hingga Desember karena musim barat dan penanaman dilakukan pada saat air surut.

Penanaman bibit mangrove ditanam secara langsung ke tanah. Pohon mangrove ditanam dilahan dengan cara membuat lubang dilahan yang telah ditentukan. Bibit ditanam secara tegak kedalam lubang yang telah disediakan dengan cara menancapkan langsung bibit satu persatu. (H.Taiyeb, 2019)

Luas lahan yang digunakan pada saat penanaman awal hanya seluas 5 Ha karena penanaman hanya dilakukan oleh 10 orang tokoh masyarakat. Bibit yang ditanam sebanyak 10.000 hingga 20.000 bibit dalam satu hektar dengan jarak $50 \mathrm{~cm} \times 50 \mathrm{~cm}$, namun penanaman ini tidak dilakukan langsung. Penanaman dilakukan secara bertahap tergantung kemampuan dalam menanam mangrove. Dalam satu bulan dilakukan penanaman dua hingga tiga kali.
Bibit diambil secara gratis di Desa Pangasa atas persetujuan masyarakat setempat. Masyarakat bekerja sama mengambil bibit untuk ditanam. Banyaknya bibit yang diambil tergantung kemampuan masyarakat dalam menanam. Pada saat menanam jarak yang digunakan adalah 50 $\mathrm{cm} \times 50 \mathrm{~cm}$. Hal ini bertujuan ketika mangrove sudah tumbuh dan besar pertumbuhannya akan rapat dan bisa menghalau ombak secara baik. Mangrove yang ditanam masyarakat secara swadaya 90\% tumbuh dengan baik. Jenis mangrove yang di tanam saat itu hanya dua jenis yaitu Rhyzophora Mucronata ( Bakau) dan Rhyzophora Apiculata ( Bakau ).

Pada masing - masing ujung areal penanaman mangrove di Tongke - Tongke dibatasi oleh Sungai Baringeng di sebelah selatan dan Sungai Tui di sebelah Utara. Kedua sungai tersebut dibagian muaranya agak dalam yaitu $\pm 87 \mathrm{~cm}$ jika air surut, namun aliran airnya tidak terlalu deras sehingga pada pencampuran air di muara salinitasnya berkisar antara $3-2 \%$ saat air pasang. Pohon - pohon bakau yang telah ditanam membentuk tingkatan diameter dan tinggi berdasarkan umur penanaman. (M.Ghufran H, 2015)

Pohon mangrove yang telah berhasil tumbuh dengan baik dilokasi penanaman agar dibuat tata aturan untuk memberikan informasi dan pendidikan kepada masyarakat luas akan pentingnya penjagaan terhadap kelestarian mangrove dipesisir serta larangan melakukan penebangan pohon mangrove. (M.Ghufran H, 2015)

Melihat perkembangan mangrove yang tumbuh dengan baik, Sainuddin salah satu inisiator penanaman mangrove kemudian membentuk kelompok penyelamatan lingkungan melalui penanaman hutan mangrove yang diberi nama Aku Cinta Indonesia ( ACI ) dan memilih H.Taiyeb sebagai ketua kelompoknya, Sainuddin sebagai Sekretaris dan Amiruddin sebagai bendahara tetapi belum secara formal.

Kelompok penyelamat lingkungan Aku Cinta Indonesia (ACI) mengajak masyarakat untuk menanam mangrove 
dengan membagi masing - masing wilayah penanaman. Kelompok inilah yang menginisiasi kegiatan penanaman mangrove dan keberhasilan masyarakat dalam menanam mangrove secara swadaya yang memberikan dampak positif.

\section{b. Peranan Pemerintah}

Keberadaan hutan mangrove wilayah pesisir merupakan daerah penghambat masuknya gelombang air laut ke darat. Untuk mencegah abrasi secara bertahap membangun pengaman pantai. Upaya didukung dengan penanaman mangrove yang dilaksanakan oleh masyarakat dan pemerintah setempat. (Bambang, 2018).

Pemerintah dalam hal ini sangat berpengaruh terhadap pelestarian mangrove yang ada di Sinjai Timur tepatnya di Desa Tongke-Tongke, dimana pemerintah dapat mensosialisasikan manfaat penanaman mangrove terhadap lingkungan salah satunya dalam pencegahan abrasi.

Kegiatan rehabilitasi mangrove tidak cukup dalam bentuk proyek oleh instansi terkait, melainkan harus merupakan suatu gerakan rehabilitasi dari berbagai lapisan masyarakat yang dimediasi/ difasilitasi oleh instansi terkait, agar upaya rehabilitasi bersifat sinergis, efektif, dan efisien. (Robert, 2016)

Pada saat penanaman hutan mangrove di Tongke - Tongke H. Badaruddin sebagai kepala Lingkungan menjadi fasilisator dalam kegiatan penanaman mangrove. Kepala Lingkungan mengajak masyarakat untuk bekerja sama dalam kegiatan penanaman demi menyelamatkan lingkungan. Masyarakat diajak untuk mengambil bibit secara gotong royong di Desa tetangga tepatnya di Desa Pangasa untuk di tanam dengan tujuan penahan abrasi.

Komitmen pemerintah sebagai fasilisator dan regulator sangat diperlukan untuk upaya konservasi sumber daya alam, termasuk mangrove. Kegiatan penanaman mangrove di Tongke - Tongke, Pemerintah kabupaten juga ikut berpartisipasi dalam kegiatan penanaman mangrove. Tetapi pemerintah Kabupaten baru mengetahui adanya tanaman mangrove di Desa Tongke- Tongke setelah 2 tahun penanaman. Bupati pada saat itu adalah Arifuddin Mattotorang. Arifuddin Mattotorang mengajak sekolah - sekolah khususnya Sekolah Menengah Atas (SMA) di Kabupaten Sinjai untuk mengadakan perkemahan sekaligus melakukan kegiatan penanaman mangrove.

Keberadaan hutan mangrove di Desa Tongke-Tongke, harus dikembangkan dalam bidang pariwsata. Dalam hal ini pemerintah sangat berperan penting dalam pengembangan keberadaan hutan mangrove dengan melakukan rehabilitasi dilapisan masyarakat sebagi fasilitator dalam pengembangannya.

\section{Kesimpulan}

Perkembangan hutan mangrove Tongke - Tongke terjadi tahun 1995 setelah mendapat piagam penghargaan Kalpataru sebagai penyelamat lingkungan hingga menjadi sebuah obyek wisata. Obyek wisata hutan mangrove Tongke Tongke ramai dikunjungi oleh wisatawan serta menjadi laboratorium pengembangan mangrove di Sulawesi Selatan. Keberadaan hutan mangrove ini memberi dampak sosial, ekonomi dan pariwisata bagi masyarakat. Berdasarkan hasil penelitian, maka dapat disimpulkan bahwa keberadaan hutan mangrove hingga mengalami perkembangan pesat terutama setelah menjadi obyek wisata alam yang menyebabkan banyak wisatawan yang datang berkunjung ataupun melakukan penelitian dan ini berdampak pada pelaku ekonomi yang turut berpartisipasi serta memanfaatkan peluang untuk meningkatkan kehidupan ekonomi yang lebih baik.

\section{E. Daftar Pustaka}

Tim Penyusun Pusat Kamus. (2007). KBBI (Kamus Besar Bahasa Indonesia) (Ketiga ed.). Jakarta: Balai Pustaka. 
Alimuddin, M. R. (2004). Mengapa Kita Belum Cinta Laut. Yogyakarta : Ombak.

Arifuddin Ismail. (2012). Agama Nelayan. Yogyakarta: Pustaka Pelajar.

BPS. (2015). Kabupaten Sinjai Dalam Angka.

Endang Retnowati. (2011). Nelayan Indonesia Dalam Pusaran Kemiskinan Struktural. Perspektif.

Hariyono. (1995). Mempelajari Sejarah Secara Efektif. Malang: Pustaka Jaya.

Haerianty Rezki Sani, Amirullah, A. (2018) 'Penetrasi Nelayan Tradisional Panaikang 1955-1970', Pattingalloang, 5(Januari-April), pp. 87-100. doi: Jurnal Pattingalloang.

Ida Bagoes Mantra. (2000). Demografi

Umum. Yogyakarta: Pustaka Pelajar.

Kuntowijoyo. (2005). Pengantar Ilmu Sejarah. Yogyakarta: Bentang.

Kusnadi. (2003). Akar Kemiskinan Nelayan. Yogyakarta: Lkis.

Mayor Polak. (1976). Sosiologi Suatu Pengantar Ringkasan Ikhtisari. Jakarta: Ichtiar Baru.

Mustaming. (2018, Maret 15). Nelayan Tradisional di Desa Panaikang.

Profil Desa Panaikang. (2017). Buku Profil Desa Panaikang Tahun 2015. Sinjai.

Rustam Tamburaka. (1999). Pengantar Ilmu Sejarah, Teori Filsafat Sejarah, Sejarah Filsafat dan Iptek. Jakarta: Rineka Cipta.

Sakka. (2018, Maret 15). Budaya Nelayan di Desa Panaikang.

Sallatang, A. (1982). Pinggawa-Sawi: suatu studi Sosiologi Kelompok Kecil. Ujungpandang: PPs-UNHAS.

Sugeng Priyadi. (2012). Metode Penelitian Pendidikan Sejarah. Yogyakarta: Ombak.

Tulisi, H. (2018, Maret 19). Kehidupan Nelayan Tradisional di Desa Panaikang. 